\title{
Levels of Inpatient Satisfaction with Health Service Provision among Patients Admitted to Nekemte Referral Hospital, Nekemte, Ethiopia
}

\author{
Tahir Hasen* \\ Department of Nursing and Midwifery, College of Health Sciences, Wollega University, \\ P.O. Box: 395, Nekemte, Ethiopia
}

\begin{abstract}
In health care services, satisfaction is a positive feeling of patients towards the health care provided to them. It is one of the methods of measuring quality of health care. Even if satisfaction is a subjective concept, it is one of the most important factors to improve health care services. The health care systems in most developing countries suffer from serious deficiencies in financing, efficiency, equity and quality and are poorly prepared to meet these challenges. The objectives of the study was to assess the level of inpatient satisfaction with health care provision among patients admitted to Nekemte Referral Hospital. An institution based cross-sectional study was conducted on inpatient satisfaction with health care provision among patients admitted to Nekemte referral Hospital from 27/10/2014 to 24/12/2014. Valid and reliable questionnaires and in-depth interviews were administered to patients admitted to the hospital during the study period. A total of 422 respondents were participated in the study with 38.6 mean ages and standard deviation of 14.7. The age ranges were 15-90 years. Protestant 229(54.3\%) was the leading religion followed by Orthodox 121(28.7\%). Oromo 362(86\%) was the major ethnic group. The overall satisfaction of inpatients with health care provision was $148(35.1 \%)$. Patient satisfaction with the attractiveness of the physical structure of the hospital were 242(57.3\%), 224(53.1\%) replied the hospital blocks were not sufficient, and $344(81.5 \%)$ replied the hospital compound was not neat, clear and planted with sufficient grasses and flowers, 283(67.1\%) respondents answered the hospital lacks sufficient waiting rooms at each clinic. Most patients $387(91.7 \%)$ were interested to be visited by their relatives;
\end{abstract} therefore, adequate time has to be allocated for visitors.

Copyright@2016 STAR Journal, Wollega University. All Rights Reserved.

Article Information

Article History:

Received : 08-11-2015

Revised : 24-02-2016

Accepted : 01-03-2016

Keywords:

Inpatient

Waiting room

Levels of satisfaction

Western Ethiopia

Nekemte Referral Hospital

*Corresponding Author:

Tahir Hasen

E-mail:

tahirhasen54@gmail.com

\section{INTRODUCTION}

Consumer satisfaction is playing an increasingly important role in quality of care reforms and health-care delivery more generally. However, consumer satisfaction studies are challenged by the lack of a universally accepted definition or measure (Carr-Hill, 1992; Ross, Stewart and Sinacore, 1995; Sitzia and Wood, 1997, Crow et al., 2002; Hudak and Wright; 2000 and Sofaer, Firminger, 2005) and by a dual focus: while some researchers focus on patient satisfaction with the quality and type of health-care services received (Linder and Pelz, 1982; Kane et al., 1997; Jackson, Chamberlin and Kroenke, 2001 and Nguyen. Thi et al., 2002) others focus on people's satisfaction with the health system more generally (Stewart, Stewart and Roter, 1989; Blendon et al., 2003 and Blendon et al., 1990 and European Commission, 2007). The importance of both perspectives has been demonstrated in the literature. For example, satisfied patients are more likely to complete treatment regimens and to be compliant and cooperative (Stewart, Stewart and Roter, 1989; Zapka et al., 1995). Research on health system satisfaction, which is largely comparative, has identified ways to improve health, reduce costs and implement reform (Blendon et al., 2003).
A study in Mozambique on satisfaction with the outpatient health care services showed $55 \%$ satisfaction rate and failure to receive prescribed medications was found to be the most common complaint associated with lower satisfaction rates. Another study in the Tororo district also concluded that the availability of drugs in the rural health facilities brought satisfaction not only to the users, but also to the providers (World development report, 2004). A study in Singapore hospitals also showed that out of the total 300 respondents, $30(11.9 \%)$ rated the service quality very good, $122(48.4 \%)$ rated the service quality good, $70(31.0 \%)$ rated the service quality fair, $18(7.1 \%)$ rated the service quality poor and $4(1.6 \%)$ rated the service quality very poor (Peter and Berman, 2000).

A study on outpatient performance of a teaching hospital in Gondar town showed $22.0 \%$ satisfaction rate (Mitike, Mekonnen and Osman, 2002). A study done at selected health facilities in six regions of Ethiopia depicted that the percentage for high mean score satisfaction with health providers' characteristics ranged from $77.25 \%$ to 93.23\%; with service characteristics $68.64 \%$ to $86.48 \%$; and satisfaction with cleanliness ranged from $76.50 \%$ to 90.57\% (Ministry of Health, 2003). 


\section{Tahir Hasen}

Another study in Tigrai Zonal Hospitals found that the client satisfaction level with the outpatient departments in the zonal hospitals was $43.6 \%$. Satisfaction was rated highest with courtesy and respect by the health workers with $93.8 \%$ satisfaction rate. Dissatisfaction was rated highest by respondents with the lack of drugs and supplies in the hospitals pharmacies with $64.9 \%$ reporting dissatisfaction (Dagnew and Zakus, 1997). In a survey undertaken in private clinics in Addis Ababa, high rates of satisfaction (64-99\%) were found in all aspects of medical care except affordability of service Charges (Mitike, Mekonnen and Osman, 2002). Another study in Jimma hospital showed $57.1 \%$ level of satisfaction with outpatient health services (Abebe et al., 2008).

In analyzing the quality of integrated healthcare, as a new form of care, $75 \%$ of the respondents were 'very satisfied' or 'rather satisfied' with the range of services offered within the opti-mum project. In addition, about $80 \%$ of the respondents would again participate in the project and recommend it. But the survey also demonstrated that there is potential for improving the provision of information (Rundle-Thiele and RussellBennett, 2010).

There is lack of studies about level of inpatient satisfaction with health service provision among patients admitted to Hospitals in western Ethiopia. Therefore, the aim of this study is to find out patient satisfaction with health services and to explore the associated factors in Nekemte Referral hospital.

\section{MATERIALS AND METHODS}

This study was conducted in Nekemte, Referral hospital found in Western Ethiopia, east Wollega zone, Oromia region, $331 \mathrm{kms}$ far away from Addis Ababa. It has an altitude of 2045 meters above sea level. Nekemte town is the capital of east Wollega zone. It is divided in to six sub cities. The total population of the town is estimated to be 96,864 (CSA, 2000).

The existing health facilities in the town include: one hospital, two health centers (both governmental), two NGO clinics, nine midlevel and 16 small private clinics, five drug stores and supplies, seven pharmacies and five rural drug vendors. The town has got 24 hours electricity and telecommunication services. Nekemte hospital is established in 1932 by Sweden missionaries. It has eight specialists, eleven general practitioners, 71 nurses, 9 health officers, 8 laboratory technicians, 7 pharmacy technicians, 2 sanitarians and 78 administrative staffs. The hospital has 178 beds. The number of patients treated at OPD level per year is estimated to be 71,178 and 7,108 patients were treated at inpatient department.

An institution based cross-sectional study was conducted in Nekemte Referral hospital. The study was conducted between 27/10/2014 to 24/12/2014. All patients admitted and treated in Nekemte Referral hospital were included. All patients admitted in all wards of Nekemte Referral hospital during data collection time.

The following assumptions were made to determine the sample size: to obtain minimum sample size, the population proportion for prevalence of inpatient satisfaction were taken to be $50 \%$, with the margin of error (desired precision) 5\%, 95\% confidence interval. The total populations of Nekemte referral hospital catchment areas
Sci. Technol. Arts Res. J., Jan-March 2016, 5(1): 69-75

were expected to be greater than 10,000 . The actual sample size was calculated using single proportion formula.

The formula to calculate the sample size was

$$
\mathrm{n}=\frac{(\mathrm{z \alpha} / 2)^{2} \mathrm{p}(1-\mathrm{p})}{\mathrm{D}^{2}}=\frac{(1.96)^{2} \times 0.5(1-0.5)}{(0.05)^{2}}=384+38=422
$$

On the sample size $10 \%$ contingency (38) were added, therefore, the total sample size was 422 .

$\mathrm{Z} \alpha / 2$ =the confidence limits of the survey result (critical value at $95 \%$ confidence interval of certainty) $=(1.96) ; \mathrm{P}=$ the proportion of study population to inpatient satisfaction $=50 \% ; \quad D=$ the desired precision of the estimate (the margin of error between the sample and population (5\%) and $n=$ the total sample size (422).

In this study Nekemte hospital was selected to study inpatient satisfactions who were admitted at the time of data collection. The sampling technique selected for the study was probability sampling (stratified and systematic). The stratification was used to see all the wards and systematic method was applied to collect data from each ward using $k=3$. There are a total of 178 beds in the hospital. The total wards bed numbers were as follows: (medical ward $=45$ beds, surgical ward $=38$, Obstetrics ward $=44$ and Pediatrics ward $=51$ beds). The data contains quantitative and qualitative analysis. For quantitative data, structured questionnaires were used and for qualitative, indepth-interview was applied.

The inclusion criteria were patients who were voluntary to participate in the study, had no history of mental illness and were able to communicate. Mentally ill, critically sick, deaf and unconscious patients who were unable to communicate were excluded from the study.

The dependent variable is levels of inpatient satisfaction and the independent variables were sociodemographic variables, method and quality of care, confidentiality and privacy, condition of the rooms and hospital structures.

Valid and reliable structured questionnaires and indepth interviews were used to collect data from respondents. Pre-test was done before the main study on clients whose number were about $10 \%$ of the total respondents and not be included in the main study. For qualitative data, in-depth interviews were used and video recorded. For patients or their attendant who can read Afaan Oromo and Amharic can fill the questionnaires by themselves because they can freely fill the questionnaires confidently. But for those patients who cannot read Afaan oromo and Amharic, the data collectors interviewed them and fill their responses. Great care was taken during the training and supervision to avoid differences in interpreting the interview schedule. For patients whose age is less than 15 years, families were interviewed for their satisfaction.

The ethical clearance was granted for the study to be conducted from Wollega University, East Wollega zonal health bureaus and the hospital. Four trained data collectors were collected the data from the hospital, the professionals commented on the contents, the appropriateness and clarity of questions, the questionnaires were seen and commented by friends, quantitative analysis was triangulated with qualitative 


\section{Tahir Hasen}

analysis, study participants were told that their responses were extremely confidential at any circumstance and they were not be coerced, Probability sampling technique was used (stratified and systematic), pre-tests were conducted on $10 \%$ of the sample size, the interviews were taken place in a separate room in the ward and the answers were treated anonymously, supervisions were done every day during data collection time to each data collectors. The questionnaires were checked by supervisors and principal investigator for its completeness and entered in SPSS for windows (version 20) and analysis were done using bivariate and multivariate logistic regression to see the effect of the independent variables on the dependent variables by controlling confounders. Statistical significance was evaluated at 0.05 levels of significance. $\mathrm{X}^{2}$ test and odds ratios were applied to see the association between the variables. Descriptive statistics were also been applied as necessary. Tables and graphs were used to present the data.

The proposal was seen by scholars and permissions were granted for the study to be conducted from Wollega University, East Wollega zonal health bureau, Nekemte hospital directors. Participation was voluntary and was clearly stated in the informed consent. The patients were
Sci. Technol. Arts Res. J., Jan-March 2016, 5(1): 69-75

also told that the information obtained from them was treated with complete confidentiality.

\section{RESULTS}

\section{Sociodemographic Variables}

A total of 422 respondents were participated in the study. The mean ages of participants were 38.6 with standard deviation of 14.7. The age ranges of participants were 15-90. The dominant age group was from 36-50 years which accounts $153(36.3 \%)$. With regard to the sex distribution, 232(54.3\%) were males and the rests were females. The sex of the respondents were weakly associated with inpatient satisfaction ( $p$-value $=0.01$, OR= 0.46). Protestant 229(55\%) and Orthodox 121(28.7\%) were the major religion. Oromo was the leading ethnic group with $362(86 \%)$ respondents. Concerning the marital status $300(71.1 \%)$ married and $88(20.9 \%)$ unmarried respondents were participated in the study. Most of the respondents were illiterate 165 (39.1\%) and those who attended primary schools were $111(26.3 \%)$ and both constitute 276(65.4\%). The occupational status of the respondents were housewives 99 (23.5\%) followed by daily laborers $85(20.1 \%)$. Most of the respondents have a family size of 4-6 members which accounts 188(44.5\%) followed by $7-10$ family members $117(27.7 \%)$.

Table 1: Socio-demographic variables of inpatients admitted to Nekemte hospital 2014.

\begin{tabular}{|c|c|c|c|c|}
\hline \multicolumn{2}{|c|}{ Socio-demographic variables } & \multirow{2}{*}{$\begin{array}{c}\text { Frequency } \\
15\end{array}$} & \multirow{2}{*}{$\begin{array}{c}\text { Percent } \\
3.6\end{array}$} & \multirow{2}{*}{$\frac{\text { Cumulative \% }}{3.6}$} \\
\hline \multirow{8}{*}{ Age } & $<18$ & & & \\
\hline & $18-25$ & 86 & 20.4 & 24.5 \\
\hline & $26-35$ & 93 & 22.0 & 47.1 \\
\hline & $36-50$ & 153 & 36.3 & 84.2 \\
\hline & $51-65$ & 53 & 12.6 & 97.1 \\
\hline & $66-75$ & 12 & 2.8 & 100.0 \\
\hline & $>75$ & 412 & 97.6 & 3.6 \\
\hline & Total & 422 & 100.0 & \\
\hline \multirow{3}{*}{ Sex } & Male & 232 & 55.0 & 55.0 \\
\hline & Female & 190 & 45.0 & 100.0 \\
\hline & Total & 422 & 100.0 & \\
\hline \multirow{7}{*}{ Occupation } & House wife & 99 & 23.5 & 23.5 \\
\hline & Daily laborer & 93 & 22.0 & 45.5 \\
\hline & Merchant & 98 & 23.2 & 68.7 \\
\hline & Student & 62 & 14.7 & 83.4 \\
\hline & Government Employee & 12 & 2.8 & 86.3 \\
\hline & Farmer & 58 & 13.7 & 100.0 \\
\hline & Total & 422 & 100.0 & \\
\hline \multirow{6}{*}{ Ethnicity } & Oromo & 363 & 86.0 & 86.0 \\
\hline & Amhara & 40 & 9.5 & 95.5 \\
\hline & Tigray & 10 & 2.4 & 97.9 \\
\hline & Gurage & 5 & 1.2 & 99.1 \\
\hline & other & 4 & .9 & 100.0 \\
\hline & Total & 422 & 100.0 & \\
\hline \multirow{5}{*}{ Educational status } & Illiterate & 165 & 39.1 & 39.1 \\
\hline & Primary & 111 & 26.3 & 65.4 \\
\hline & Secondary & 72 & 17.1 & 82.5 \\
\hline & College and above & 74 & 17.5 & 100.0 \\
\hline & Total & 422 & 100.0 & \\
\hline \multirow{7}{*}{ Average monthly income } & $<1000$ & 161 & 38.2 & 38.2 \\
\hline & $1000-2000$ & 74 & 17.5 & 55.7 \\
\hline & $2001-3000$ & 47 & 11.1 & 66.8 \\
\hline & $3001-4000$ & 43 & 10.2 & 77.0 \\
\hline & $4001-5000$ & 53 & 12.6 & 89.6 \\
\hline & $>5000$ & 44 & 10.4 & 100.0 \\
\hline & Total & 422 & 100.0 & \\
\hline \multirow{5}{*}{ Family size } & $1-3$ & 100 & 23.7 & 23.7 \\
\hline & $4-6$ & 188 & 44.5 & 68.2 \\
\hline & $7-10$ & 117 & 27.7 & 96.0 \\
\hline & $>10$ & 17 & 4.0 & 100.0 \\
\hline & Total & 422 & 100.0 & \\
\hline
\end{tabular}




\section{Tahir Hasen}

\section{Levels of Inpatient Satisfaction}

The overall satisfaction of patients with health care provision at Nekemte referral hospital was 148(35.1\%). Among the satisfied patients 66(44.6\%) were highly satisfied, 76(51.4\%) moderately satisfied and Neutral $6(4.1 \%)$. With regard to the physical structures of the hospital compounds $242(57.3 \%)$ responded it is attractive. Attractiveness of the physical structure of the hospital is statistically significant with inpatient satisfaction at $(P$ values of 0.01 and $O R=3.275$ ). Two hundred eighty three (67.1\%) of the respondents answered the hospital lacks sufficient waiting rooms at each clinic. This is statistically significant with inpatient satisfaction at $(P$-value $=0.01$, $\mathrm{OR}=3.113$ ). The degree of satisfaction of respondents with the cleanliness of the waiting rooms indicated $117(27.7 \%)$ were highly satisfied, $64(15.2 \%)$ moderately satisfied, 98(23.2\%) neutral, $113(26.8 \%)$ moderately dissatisfied and $30(7.1 \%)$ highly dissatisfied. The presence of sufficient waiting rooms at each clinic is highly associated with inpatient satisfaction at $(P$ value $=0.01, \quad \mathrm{OR}=3.371)$. The degree of inpatient satisfaction with the overall comfort of the waiting rooms were high for $90(21.3 \%)$, moderate for $37(8.8 \%)$, neutral for $18(4.3 \%)$, moderately dissatisfied for $117(41.9 \%)$ and highly dissatisfied $100(23.7 \%)$.

The levels of inpatient satisfaction with the overall cleanliness of the examination rooms were as follows:
Sci. Technol. Arts Res. J., Jan-March 2016, 5(1): 69-75

highly satisfied $150(35.5 \%)$, moderately satisfied 240(56.9\%), Neutral 25(5.9\%) and dissatisfied 7(1.6\%) (figure 4). Among the factors patients were most dissatisfied were nearly more than one-third 140(33.2\%) dissatisfied due to lack of economic problems, nearer to one-fourths 100(23.7\%) were dissatisfied from Stigma and discrimination, $81(19.2 \%)$ were dissatisfied with lack of quality of care, $71(16.8 \%)$ absence of timely services and $30(7.1 \%)$ dissatisfied with professional incompetence (figure 1). Two hundred seventy (64\%) of the respondents believe that the hospital is constructed on appropriate site. The appropriateness of the site of the hospital construction is significant with inpatient satisfaction at ( $p$ value $=0.01, \mathrm{OR}=3.343)$. Most inpatients $344(81.5 \%)$ responded the hospital compound was not neat, clear and not planted with sufficient grasses and flowers. This is statistically significant with inpatient satisfaction at $(P$ value $=0.01$, OR $=3.411)$. The levels of inpatient satisfaction when they were visited by their families were $387(91.7 \%)$. The proportions of inpatient dissatisfaction when visitors were restricted were $351(83.2 \%)$. The degree of their dissatisfaction with restriction of visitors were highly dissatisfied $61(14.5 \%)$, fairly dissatisfied $223(52.8)$ and neutral $138(32.7 \%)$. The numbers of inpatient disturbances with visitors of other patients were $89(21.1 \%)$.

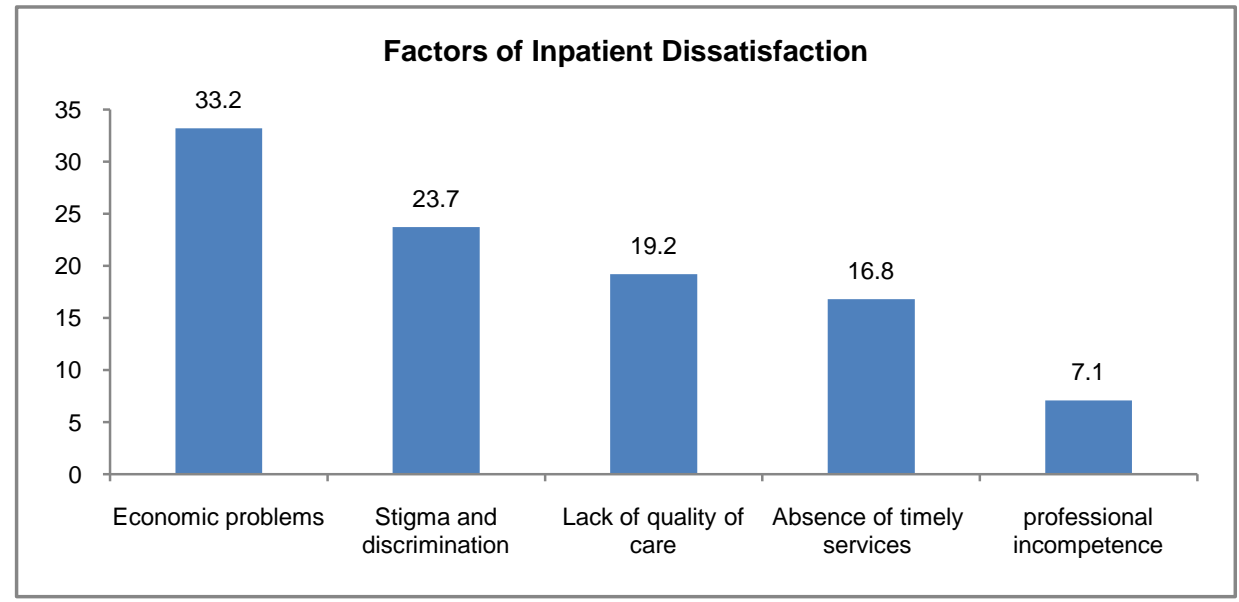

Figure 1: Percentage of factors of inpatient satisfaction with the health care services

Costs of the services were one of the factors for client satisfaction. About $389(92.2 \%)$ of the respondents were served in the hospital with payment. Among patients who were paying for the services $288(54 \%)$ replied the payments were fair. But 161(38.2\%) said it is unfair. The degree of inpatient satisfaction with the costs of the services provided in the hospital were highly satisfied $113(26.8 \%)$, moderately satisfied $111(26.3 \%)$, neutral $121(28.7 \%)$, moderately dissatisfied $60(14.2 \%)$, highly dissatisfied 17(4.0) (figure 2). More than 233(55.2\%) respondents were not comfortable with the cleanliness of the laboratory rooms (table 2).

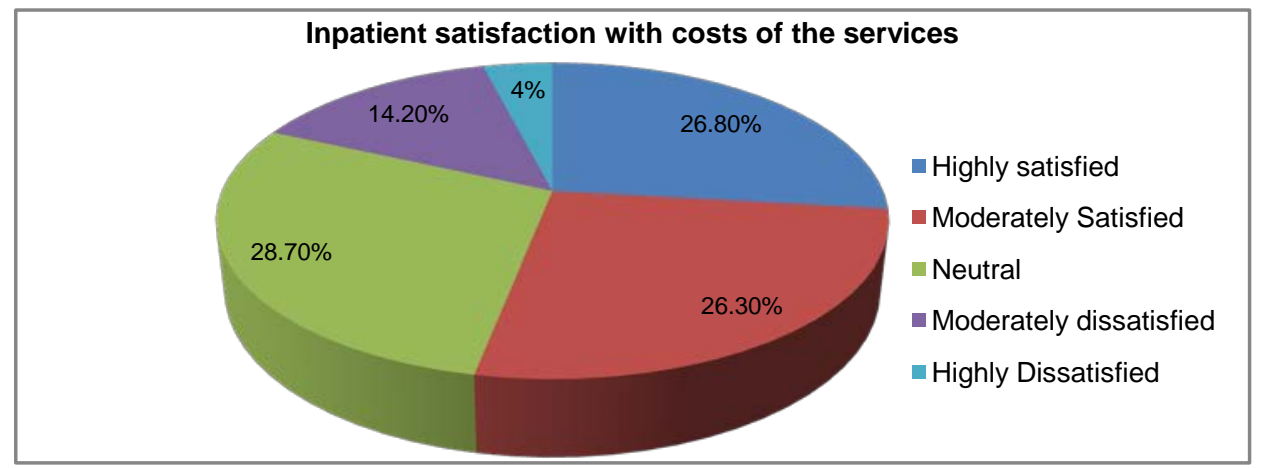

Figure 2: Percentage distributions of factors of inpatient satisfaction with the cost of services 
Table 2: Variables associated with inpatient satisfaction, Nekemte, Ethiopia, 2014

\begin{tabular}{|c|c|c|c|c|c|c|}
\hline \multirow{3}{*}{$\begin{array}{l}\text { Independent Variables having } \\
\text { Association with the } \\
\text { Dependent Variable }\end{array}$} & \multirow{3}{*}{ Characteristics } & \multicolumn{2}{|c|}{ Dependent Variable } & \multirow{3}{*}{ Total } & \multirow{3}{*}{$P$-value } & \multirow{3}{*}{ OR } \\
\hline & & \multicolumn{2}{|c|}{$\begin{array}{l}\text { Have you been Satisfied with } \\
\text { the Care Rendered to You? }\end{array}$} & & & \\
\hline & & Yes & No & & & \\
\hline \multirow{3}{*}{ Sex } & Male & 63 & 169 & 232 & \multirow{2}{*}{0.01} & \multirow{2}{*}{0.46} \\
\hline & Female & 85 & 105 & 190 & & \\
\hline & Total & 148 & 274 & 422 & 0.05 & 1.85 \\
\hline \multirow{3}{*}{$\begin{array}{l}\text { Is the physical structure of the hospital } \\
\text { attractive? }\end{array}$} & Yes & 111 & 131 & 242 & \multirow{3}{*}{0.01} & \multirow{3}{*}{3.275} \\
\hline & No & 37 & 143 & 180 & & \\
\hline & Total & 148 & 274 & 422 & & \\
\hline \multirow{3}{*}{$\begin{array}{l}\text { Do the hospital blocks sufficient for all } \\
\text { services rendered in the hospital? }\end{array}$} & Yes & 96 & 102 & 198 & \multirow{3}{*}{0.01} & \multirow{3}{*}{3.113} \\
\hline & No & 52 & 172 & 224 & & \\
\hline & Total & 148 & 274 & 422 & & \\
\hline \multirow{3}{*}{$\begin{array}{l}\text { Do you believe that the hospital } \\
\text { constructed on appropriate site? }\end{array}$} & Yes & 119 & 151 & 270 & \multirow{3}{*}{0.01} & \multirow{3}{*}{3.343} \\
\hline & No & 29 & 123 & 152 & & \\
\hline & Total & 148 & 274 & 422 & & \\
\hline \multirow{3}{*}{$\begin{array}{l}\text { Is the hospital compound neat, clear and } \\
\text { planted with sufficient grasses and flowers? }\end{array}$} & Yes & 46 & 32 & 78 & \multirow{3}{*}{0.01} & \multirow{3}{*}{3.411} \\
\hline & No & 102 & 242 & 344 & & \\
\hline & Total & 148 & 274 & 422 & & \\
\hline \multirow{3}{*}{$\begin{array}{l}\text { Does the hospital have sufficient waiting } \\
\text { rooms at each clinic? }\end{array}$} & Yes & 75 & 64 & 139 & \multirow{3}{*}{0.01} & \multirow{3}{*}{3.371} \\
\hline & No & 73 & 210 & 283 & & \\
\hline & Total & 148 & 274 & 422 & & \\
\hline \multirow{6}{*}{$\begin{array}{l}\text { How much are you satisfied with the } \\
\text { cleanliness of the waiting area? }\end{array}$} & Very satisfied & 36 & 31 & 67 & \multirow{6}{*}{0.01} & \multirow{6}{*}{1.854} \\
\hline & Satisfied & 19 & 29 & 48 & & \\
\hline & Neutral & 50 & 76 & 126 & & \\
\hline & Dissatisfied & 31 & 114 & 145 & & \\
\hline & Very dissatisfied & 12 & 24 & 36 & & \\
\hline & Total & 148 & 274 & 422 & & \\
\hline Are the guardians accepting you warmly & Yes & 46 & 51 & 97 & 0.01 & 1851 \\
\hline and friendly? & No & 102 & 223 & 325 & 0.01 & 1.051 \\
\hline & Total & 148 & 274 & 422 & & \\
\hline Are the card room staffs polite? & Yes & 62 & 77 & 139 & 0.01 & 1844 \\
\hline Are me card roum stails poilte? & No & 86 & 197 & 283 & 0.01 & $1.04+4$ \\
\hline & Total & 148 & 274 & 422 & & \\
\hline Are the card room staffs discriminating & Yes & 110 & 141 & 251 & 0.01 & 2.73 \\
\hline patients? & No & 38 & 133 & 171 & 0.01 & 2.13 \\
\hline & Total & 148 & 274 & 422 & & \\
\hline
\end{tabular}

\section{DISCUSSION}

The most important reason to conduct inpatient satisfaction surveys is that they provide the ability to identify and resolve potential problems before they become serious. The finding of this study showed the above mentioned results and will be compared with other findings as follows.

The overall satisfaction of inpatients with health care provision at Nekemte referral hospital was 148(35.1\%). This finding was higher than the study conducted on outpatient performance of a teaching hospital in Gondar town that showed $22.0 \%$ satisfaction rate (Mitike, Mekonnen and Osman, 2002). But it is lower than a study done in Mozambique on satisfaction with the outpatient health care services 55\%, again a study done in Tigrai Zonal Hospitals found that the client satisfaction level with the outpatient departments in the zonal hospital was 43.6\% and a study done at selected health facilities in six regions of Ethiopia depicted that the percentage for high mean score satisfaction with service characteristics
$68.64 \%$ to $86.48 \%$; and satisfaction with cleanliness ranged from $76.50 \%$ to $90.57 \%$ (Ministry of Health, 2003). The possible differences might be all the above mentioned results were conducted on outpatient department.

Cleanness of the hospital is one of the main activities in all professionals. Cleanness is both helpful both for sight and prevent or reduce occurrence of microorganisms. According to this finding, the inpatient satisfaction with cleanness of the waiting rooms was $241(57.1 \%)$ including those who feel neutral and 344 $(81.5 \%)$ the respondents replied, the hospital compound was not neat, clear and planted with sufficient grasses and flowers ( $p$-value=0.01 and $O R=3.411$ ). This finding is lower than a study done at selected health facilities in six regions of Ethiopia depicted that the percentage for high mean score satisfaction with cleanliness ranged from $76.50 \%$ to $90.57 \%$ (Ministry of Health, 2003). These also is a warning sign to the hospital staffs and administrators 


\section{Tahir Hasen}

to give due attention to improve the cleanness of the hospital.

Inpatient satisfaction with the attractiveness of the physical structure of the hospital were $242(57.3 \%)$, the insufficiency of the hospital blocks 224(53.1\%), the hospital lacks sufficient waiting rooms at each clinic 283(67.1\%). These all findings showed relatively half and lower satisfaction levels with regard to the hospital infrastructures. They all were statistically significant with inpatient satisfaction ( $p$-value $=0.01$ and $O R=3.275, p$ value $=0.01$ and $\mathrm{OR}=3.113, P$-value $=0.01$ and $\mathrm{OR}=3.371$, respectively. When these problems were critically viewed it can simply be resolved by the hospital staffs. It does not require a sophisticated technology and huge budget except adding the hospital blocks.

Two hundred eighty three (67.1\%) of the card room staffs were not polite for their clients and 251(59.5\%) of them were discriminating their patients. More than three fourth $325(77 \%)$ of the guardians were not treating their clients in a friendly manner. This finding is also triangulated with the qualitative finding that clients replied "In the card room there is discrimination between the urban and rural people. They give cards for urban people first who were lined behind the rural people. Again six of the eight respondents described the card room staffs were not treating their patients properly and four of the eight respondents commented the guardians were not listening to the ideas of customers". This finding is opposing with Peter Senge's definition of quality, which is "whatever concerns the consumer", in the health department, quality refers to "whatever concerns the patient" (Dagnew and Zakus, 1997). And in the future, successful hospitals would be considered those which will include the patients opinion in the evaluation system of the quality of the provided services and will take it under serious consideration during the taking of all the administrative and financial decisions process (Abebe et al., 2008). Therefore the hospital has to work on the in the improvement of the activities of the guardians and the card room staffs even though there were work load in this areas.

Among the admitted patients 387(91.7\%) were interested when they were visited by their families again $351(83.2 \%)$ were dissatisfied when visitors were restricted not to visit them. The percentages of admitted patients who were disturbed by the noises of visitors were $89(21.1 \%)$. The above findings showed that most inpatients want their families to visit them and they were dissatisfied when their visitors were restricted. The finding of this study showed that the degree of patients dissatisfaction with restriction of their families were highly dissatisfied 54(12.8\%), moderately dissatisfied $184(43.6 \%)$, neutral $113(26.8 \%)$. This means more than $56 \%$ of inpatients were dissatisfied or stressed due to restriction of their families excluding those who were neutral1 13(26.8\%). When patients were stressed their healing time may be prolonged. Again there were low magnitudes of disturbances of patients by visitors of other patients which were highly dissatisfied 18(4.3\%), moderately dissatisfied $40(9.5 \%)$ and neutral $31(7.3 \%)$. From this finding one can conclude social therapy is a crucial medicine for admitted patients.
Sci. Technol. Arts Res. J., Jan-March 2016, 5(1): 69-75

Respondents satisfaction levels with the overall effectiveness of the services were highly satisfied $159(37.7 \%)$, moderately satisfied $108(25.6 \%)$, neutral $101(23.9 \%)$, moderately dissatisfied $42(10 \%)$, highly dissatisfied $12(2.8 \%)$. This finding was comparable with a study conducted in Singapore hospitals that showed $30(11.9 \%)$ rated the service quality very good, 122 $(48.4 \%)$ rated the service quality good, $70(31.0 \%)$ rated the service quality fair, $18(7.1 \%)$ rated the service quality poor and $4(1.6 \%)$ rated the service quality very poor.

\section{CONCLUSIONS}

Patient satisfaction is a multifactor issue. For holistic satisfaction to occur in addition to patient-provider relationship and availability of resources, infrastructure quality, adequacy, cleanliness, and availability of patient waiting areas should be given due attention. Patients were mostly dissatisfied with lacks of sufficient waiting rooms at each clinic, the cleanliness of the waiting rooms, the comfort of the waiting rooms, the cleanliness of the examination rooms, Lack of quality of care, absence of timely services, Costs of the services and cleanliness of the laboratory rooms were factor that need consideration.

\section{Acknowledgements}

First of all I am grateful to Wollega University for funding this project, and also I send my deepest appreciation to Nekemte Referral Hospital administrative and technical staffs, data collectors and respondents all my friends and those who gave me their precious time in conducting this research paper.

\section{Conflict of Interest}

None Declared

\section{REFERENCES}

Abebe, B., Girum, T., Yared, M., Woldemariam, G., Ambaye, D., Asnakech, M., Amare, D. (2008). Levels of outpatient satisfaction at selected health facilities in Six regions of Ethiopia. Ethiopian Journal of Health Development 22(1): 42-48.

Blendon, R.J., Leitman, R., Morrison, I., Donelan, K. (1990). Satisfaction with health systems in ten nations. Health Affairs (Millwood) 9: 185-192.

Blendon, R.J., Schoen, C., DesRoches, C., Osborn, R., Zapert, K. (2003). Common Concerns Amid Diverse Systems: Health Care Experiences in Five Countries. Health Affairs (Millwood) 22: 106-21.

Blendon. R.J., Benson, J.M., DesRoches, C.M., Weldon, K.J. (2003). Using opinion surveys to track the public's response to a bioterrorist attack. Journal of Health Communications 8(1): 83-92.

Carr-Hill, R.A. (1992). The Measurement of Patient Satisfaction. Journal of Public Health Medicine 14: 236249.

Crow. R., Gage, H., Hampson, S., Hart, J., Kimber, A., Storey L. (2002). The Measurement of Satisfaction with Healthcare: Implications for Practice from a Systematic Review of the Literature. Health Technology Assessment 6: 1-244.

Dagnew, M., Zakus, D. (1997). Community Perception on OPD Performance of a Teaching Hospital in Gondar town. Ethiopia. Ethiopian Medical Journal Development 35: 153-160. 


\section{Tahir Hasen}

European Commission, Directorate General Press and Communication, Public Opinion Analysis Sector (2007). Candidate countries eurobarometer.2, 2002 SeptemberOctober 2002. [Candidate Countries Eurobarometer Survey Series]. Ann Arbor, MI:Inter-University Consortium for Political \& Social Research. Available from: http://www.icpsr.umich.edu/cocoon/ICPSR/STUDY/04062 .xml [accessed on 26 February 2009].

Hudak, P.L., Wright, J.G. (2000). The characteristics of patient satisfaction measures. Spine 25: 3167-3177.

Jackson, J.L., Chamberlin, J., Kroenke, K. (2001). Predictors of patient satisfaction. Social Science Medicine 52:609620.

Kane. R.L., Maciejewski, M., Finch, M. (1997). The relationship of patient satisfaction with care and clinical outcomes. Medical Care 35: 714-730.

Linder Pelz S. (1982). Social psychological determinants of patient satisfaction: A test of five hypotheses. Social Science Medicine 16: 583-589.

Ministry of Health (2003). Health and Health related indicators 2003 E.C. DKT Ethiopia. Policy Planning Directorate, $\mathrm{MOH}$.

Mitike, G., Mekonnen, A., Osman, M. (2002). Satisfaction on outpatient services in hospitals of the Amhara region. Ethiopian Medical Journal 40: 387-395.
Sci. Technol. Arts Res. J., Jan-March 2016, 5(1): 69-75

Nguyen Thi, P.L., Briancon, S., Empereur, F., Guillemin, F. (2002). Factors Determining Inpatient Satisfaction with Care. Social Science Medicine 54: 493-504.

Peter A. Berman (2000). A decade of health sector reform in developing countries. USAID.

Ross C.K., Stewart, C.A., Sinacore, J.M. (1995). A comparative study of seven measures of patient satisfaction. Medical Care 33: 392-406.

Sitzia, J., Wood, N. (1997). Patient satisfaction: a review of issues and concepts. Social Science Medicine 45:18291843.

Sofaer, S., Firminger, K. (2005). Patient perceptions of the quality of health services. Annual Review of Public Health 26: 513-559.

Stewart, M., Stewart, M., Roter, D. (1989). Which facets of communication have strong effects on outcome: a metaanalysis. In: Stewart, M., Roter, D. Communicating with medical patients. Newbury Park, CA: Sage Publications; pp. 183-96.

World Development Report (2004). Making Services Work for the Poor People. http://hdl.handle.net/10986/5986

Zapka, J.G., Palmer, R.H., Hargraves, J.L., Nerenz, D., Frazier, H.S., Warner, C.K. (1995). Relationship of Patient Satisfaction with Experience of System Performance and Health Status. Journal of Ambulatory Care Manage 18: 73-83. 